\title{
Article \\ pH-Sensitive Chitosan Nanoparticles for Salivary Protein Delivery
}

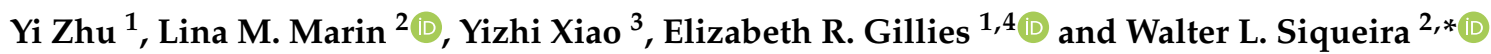 \\ 1 School of Biomedical Engineering, The University of Western Ontario, 1151 Richmond Street, \\ London, ON N6A 3K7, Canada; yzhu336@uwo.ca (Y.Z.); egillie@uwo.ca (E.R.G.) \\ 2 College of Dentistry, University of Saskatchewan, 105 Wiggins Rd, Saskatoon, SK S7N 5E4, Canada; \\ lina.marin@usask.ca \\ 3 Schulich Medicine and Dentistry, The University of Western Ontario, 1151 Richmond Street, \\ London, ON N6A 5C1, Canada; yxiao32@uwo.ca \\ 4 Department of Chemistry, Department of Chemical and Biochemical Engineering, The University of Western \\ Ontario, 1151 Richmond Street, London, ON N6A 5B7, Canada \\ * Correspondence: walter.siqueira@usask.ca
}

Citation: Zhu, Y.; Marin, L.M.; Xiao, Y.; Gillies, E.R.; Siqueira, W.L. pH-Sensitive Chitosan Nanoparticles for Salivary Protein Delivery. Nanomaterials 2021, 11, 1028. https:// doi.org/10.3390/nano11041028

Academic Editor: Edgar O'Rear

Received: 17 March 2021

Accepted: 14 April 2021

Published: 17 April 2021

Publisher's Note: MDPI stays neutral with regard to jurisdictional claims in published maps and institutional affiliations.

Copyright: (c) 2021 by the authors. Licensee MDPI, Basel, Switzerland. This article is an open access article distributed under the terms and conditions of the Creative Commons Attribution (CC BY) license (https:// creativecommons.org/licenses/by/ $4.0 /)$.

\begin{abstract}
Salivary proteins such as histatins (HTNs) have demonstrated critical biological functions directly related to tooth homeostasis and prevention of dental caries. However, HTNs are susceptible to the high proteolytic activities in the oral environment. Therefore, $\mathrm{pH}$-sensitive chitosan nanoparticles (CNs) have been proposed as potential carriers to protect proteins from enzymatic degradation at physiological salivary $\mathrm{pH}$. Four different types of chitosan polymers were investigated and the optimal formulation had good batch to batch reproducibility, with an average hydrodynamic diameter of $144 \pm 6 \mathrm{~nm}$, a polydispersity index of $0.15 \pm 0.04$, and a zeta potential of $18 \pm 4 \mathrm{mV}$ at a final $\mathrm{pH}$ of 6.3. HTN3 encapsulation and release profiles were characterized by cationic polyacrylamide gel electrophoresis. The CNs successfully encapsulated HTN3 and selectively swelled at acidic pH to facilitate HTN3 release. Protection of HTN3 against enzymatic degradation was investigated in diluted whole saliva. HTN3 encapsulated in the CNs had a prolonged survival time compared to the free HTN3. CNs with and without HTN3 also successfully reduced biofilm weight and bacterial viability. The results of this study have demonstrated the suitability of CNs as potential protein carriers for oral applications, especially for complications occurring at acidic conditions.
\end{abstract}

Keywords: protein carrier; drug delivery; polymeric nanoparticles; biopolymers

\section{Introduction}

Saliva is a complex fluid composed of proteins, enzymes, and a variety of electrolytes. Many physiological functions, such as chewing, digestion, wetting, and lubrication are regulated by saliva [1]. The concentration of proteins present in the saliva may be used to monitor oral health, as the severity and occurrence of oral diseases have been associated with the composition and quantitative changes in salivary proteins [2]. Many of the salivary proteins are active in the regulation of tooth homeostasis, either by directly exerting antimicrobial effects or interfering with microbial colonization [3]. Examples include statherin, histatins (HTNs), defensins, lactoferrin, and mucin [4]. In particular, the HTNs are of great interest because these proteins are multifunctional. They have demonstrated biological functions including the inhibition of calcium and phosphate precipitation on enamel and antimicrobial activities, which are directly related to the regulation of oral homeostasis [5-7]. The HTNs mainly consist of HTN1, HTN3, and HTN5, and each supplies about $20-30 \%$ of the total HTN pool [8]. HTN1 is the only phosphorylated HTN able to reduce bacterial colonization on tooth surfaces [9]. HTN5 has the most potent antifungal activity against the pathogenic yeast Candida albicans [10]. HTN3 was demonstrated to be the most effective in killing against Streptococcus mutans (S. mutans) [11], which is a significant contributor towards dental caries. 
These proteins are often present in low concentrations inside the oral cavity due to the high proteolytic activity of saliva [12,13]. Therefore, we proposed a delivery system to encapsulate and protect these proteins for their use as inhibitors of tooth decay. The use of stimulus-responsive polymeric nanoparticles synthesized from natural polymers has recently gained substantial attention, as such smart delivery systems have the potential to improve the overall colloidal stability of the encapsulated molecules and modulate pharmacokinetics, often resulting in reduced toxicity and enhanced efficacy [14-17]. The encapsulated cargo can be released in a stimulus-responsive manner. Examples of stimuli include changes in $\mathrm{pH}$, ionic strength, temperature, UV light, magnetic field, or the presence of specific biological molecules [18-21]. In particular, for delivering drugs to the oral cavity, it would be ideal for the delivery system to remain stable at physiological salivary $\mathrm{pH}$ and selectively release the encapsulated cargo under acidic conditions. The $\mathrm{pH}$-responsive property is crucial because the oral environment acidifies following carbohydrate intake as a result of the consumption of food and beverages. These conditions promote the development of oral diseases such as dental caries and dental erosion [22,23].

Many polymer-based materials have been studied for applications in controlled drug delivery, including naturally occurring biopolymers. For instance, chitosan is a copolymer composed of $N$-acetyl-D-glucosamine and $\beta(1-4)$ linked D-glucosamine [24]. It is mainly obtained through the deacetylation of chitin under alkaline chemicals [25]. Chitin is a biopolymer found in the exoskeletons of crustaceans, insects, and some fungi [26]. As the only known naturally occurring polycationic polysaccharide and with its ability to interact with anionic molecules, chitosan and its derivatives have been studied extensively for applications in the agricultural, medicinal, and pharmaceutical industries [27-29].

Previous studies have utilized chitosan in toothpaste as an antimicrobial agent due to its broad antimicrobial spectrum, covering both Gram-negative and Gram-positive bacteria and fungi $[30,31]$. Aside from its antimicrobial effect, chitosan also offers other advantages including biodegradability [32] and biocompatibility [33]. It also exhibits pH-dependent solubility due to the presence of amino groups on the polymer chains [34]. The functional amino groups can serve as platforms for interactions with other anionic molecules, where the choice of anionic molecules depends on the intended applications.

Chitosan nanoparticles (CNs) have been commonly used to deliver therapeutic agents, such as insulin [35], tretinoin [36], and doxorubicin [37]. In the current work, to the best of our knowledge, for the first time we propose $\mathrm{pH}$-sensitive chitosan nanoparticles for salivary protein delivery. We hypothesize that salivary protein-loaded CNs can selectively release the encapsulated proteins under low $\mathrm{pH}$ environments, offer protection against proteolysis at the physiological salivary $\mathrm{pH}$, and reduce $S$. mutans biofilm formation on hydroxyapatite. To test these hypotheses, HTN3 was selected as the target protein, and our objectives were to: (1) optimize $\mathrm{CN}$ formulation via ionic gelation with four different types of chitosan polymers; (2) characterize both blank and HTN3-loaded CNs; (3) quantify encapsulation and release profiles of HTN3; (4) assess the protection offered by encapsulation against enzymatic degradation in human saliva; and (5) evaluate the effectiveness of HTN3-loaded CNs in reducing $S$. mutans biofilm formation.

\section{Materials and Methods}

\subsection{Materials}

Ultra-low molecular weight (MW) chitosan $(20 \mathrm{~kg} / \mathrm{mol}, 91 \%$ deacetylated) and low MW chitosan (1) (250 kg/mol, 91\% deacetylated) were purchased from Glentham Life Sciences (Corsham, UK). The other low MW chitosan (2) (50-190 kg/mol, 75-85\% deacetylated), medium MW chitosan (190-310 kg/mol, 75-85\% deacetylated), and ZipTip C18 pipette tips were acquired from Millipore Sigma (Oakville, ON, Canada). All filters, including 0.45 and $0.22 \mu \mathrm{m}$ syringe filters and 10k Nanosep filters were purchased from Pall Corporation (Mississauga, ON, Canada). HTN3 was acquired from Synpeptide Co., Ltd. (Shanghai, China). S. mutans UA159 was kindly donated by Dr. Yoav Finer from the University of Toronto (Toronto, ON, Canada). Ceramic hydroxyapatite discs with 
$5 \mathrm{~mm}$ diameter and $2 \mathrm{~mm}$ thickness were obtained from Clarkson Chromatography Products Inc. (South Williamsport, PA, USA). Bicinchoninic acid assay kit was acquired from Thermo Fisher Scientific (Mississauga, ON, Canada). All other chemicals, including sodium tripolyphosphate (TPP), were purchased from Millipore Sigma (Oakville, ON, Canada).

\subsection{Optimized CNs Preparation}

The ionic gelation procedure described previously was modified to optimize CNs synthesis [38]. Briefly, preliminary experiments were done to assess the effect of chitosan molar mass and degree of deacetylation, $\mathrm{pH}$ of chitosan/TPP solutions, and chitosan to TPP mass ratios on $\mathrm{CN}$ characteristics. These particle preparations were performed in triplicate. After determining the optimal conditions, unloaded $\mathrm{CNs}$ were synthesized by dissolving $100 \mathrm{mg}$ of ultra-low MW chitosan in $100 \mathrm{~mL}$ of $0.4 \% v / v$ concentrated $\mathrm{HCl}$. The $\mathrm{pH}$ of the chitosan solution was adjusted to 5.9 and the solution was filtered through a $0.45 \mu \mathrm{m}$ syringe filter. Then, $100 \mathrm{mg}$ of TPP was dissolved in $100 \mathrm{~mL}$ of Milli-Q water, its $\mathrm{pH}$ was adjusted to 6.0 and solution was filtered through a $0.22 \mu \mathrm{m}$ syringe filter. Finally, $0.36 \mathrm{~mL}$ of TPP solution was added dropwise into $2.5 \mathrm{~mL}$ of chitosan solution under constant stirring at $700 \mathrm{rpm}$, such that the mass ratio of chitosan to TPP was 6.94:1. HTN3-loaded CNs were synthesized by mixing HTN3 with the chitosan solution before ionic gelation with TPP. Briefly, $0.29 \mathrm{~mL}$ of the $0.1 \% \mathrm{w} / \mathrm{v}$ TPP solution was introduced dropwise into $2 \mathrm{~mL}$ of $0.1 \% w / v$ chitosan and $0.0025 \% w / v$ HTN3 under constant stirring at $700 \mathrm{rpm}$. The loading ratio of chitosan to HTN3 by mass was $40: 1$, and $0.45 \mathrm{~mL}$ of the suspension contained $10 \mu \mathrm{g}$ of HTN3. The final $\mathrm{pH}$ of the nanoparticle solution was 6.3.

\subsection{Characterizations of $\mathrm{CNs}$}

Unloaded CNs and HTN3-loaded CNs were initially characterized by measuring the Z-average particle diameter, polydispersity index (PDI), and zeta potential by dynamic light scattering (DLS, Malvern Zetasizer Nano ZS instrument, Malvern Instruments Ltd, Malvern, UK) at a wavelength of $630 \mathrm{~nm}$ and a constant temperature of $25^{\circ} \mathrm{C}$. To determine the morphology of $\mathrm{CNs}$, an aliquot from each $\mathrm{CNs}$ suspension was firstly desalted by dialyzing it against $1 \mathrm{~L}$ of deionized water for $3 \mathrm{~h}$ under constant stirring, using a $50 \mathrm{~kg} / \mathrm{mol}$ MW cut-off regenerated cellulose dialysis tubing (Spectrum Labs, New Brunswick, NJ, USA). Then, samples were placed onto Formvar ${ }^{\circledR}$-coated copper grid, dried overnight under an air atmosphere, and the morphology of the $\mathrm{CNs}$ was visualized by transmission electron microscopy (TEM, Philips CM10, Philips, Amsterdam, The Netherlands) at $80 \mathrm{kV}$. To investigate the $\mathrm{pH}$-dependence of $\mathrm{CN}$ size, initial (time $=0 \mathrm{~min}$ ) particle size measurements were taken at a starting $\mathrm{pH}$ of 6.3. The $\mathrm{pH}$ of the suspension was then adjusted to 3.0, 4.0, or 5.0. After the $\mathrm{pH}$ adjustments, particle size, $\mathrm{PDI}$, and zeta potential were assessed by DLS at 10, 20, 30, 60, 120, and $240 \mathrm{~min}$. To evaluate colloidal stability, CNs were stored at $4{ }^{\circ} \mathrm{C}$ for 61 days. Particle size and zeta potential were measured by DLS on days $1,10,15$, $22,30,35,45,52$, and 61 .

\subsection{Encapsulation and Release of HTN3}

To assess the pH-dependent release of HTN3 from HTN3-loaded CNs, $0.05 \mathrm{~mL}$ of buffer ( $25 \mathrm{mM}$ phosphate buffer $/ 500 \mathrm{mM} \mathrm{NaCl}$ solution, $\mathrm{pH} 6.8$ ), was added to $0.45 \mathrm{~mL}$ of HTN3-loaded CNs suspension. The $0.5 \mathrm{~mL}$ of suspension was then filtered with a $10 \mathrm{kDa}$ cut-off Nanosep filter by centrifuging the suspension at $14,000 \times g$ for $10 \mathrm{~min}$ to separate free HTN3 (4063 Dalton) from the encapsulated CNs. The filtrate was collected to determine encapsulation efficiency by cationic polyacrylamide gel electrophoresis (cationicPAGE) [39]. The $\mathrm{pH}$ of the retentate on top of the filter was adjusted to $\mathrm{pH} 3.0,4.0$, or 5.0 and incubated at $37^{\circ} \mathrm{C}$ for $30 \mathrm{~min}$. The suspension was centrifuged again, allowing the passage of released HTN3 through the filter. Subsequently, the filtrate was collected to determine the extent of protein release by cationic-PAGE, using pure HTN3 as a reference control. HTN3 encapsulation efficiency was tested for loading ratios of $2 \%, 5 \%$, and $10 \%$ $w / w$ (HTN3 to chitosan). Encapsulation samples were prepared as previously described 
with modifications to the mass ratio of HTN3 to chitosan. The encapsulation efficiency was determined by Image Lab (BioRad) via the relative quantity tool, corresponding to the ratio of the band volume and intensity divided by the reference (HTN3 standard) band volume and intensity. To evaluate the cumulative release of HTN3, HTN3-loaded CNs were prepared as previously described. Then, the retentate on top of the filter was incubated for $30,60,90,120,150,180$, and $210 \mathrm{~min}$ at $37^{\circ} \mathrm{C}$ in buffer solutions with different $\mathrm{pH}$ values $(6.8,3.0,4.0$, or 5.0$)$. Then, samples were centrifuged at $14,000 \times g$ for $10 \mathrm{~min}$ to separate the released protein from the CNs. Subsequently, the filtrate was collected. This procedure was repeated for each time point and the filtrate and a HTN3 standard were analyzed by cationic-PAGE as previously described. The ability of the HTN3-loaded CNs to release HTN3 under $\mathrm{pH}$-cycling conditions, reflecting the $\mathrm{pH}$ changes that occur in the oral cavity, was determined by incubating the $\mathrm{CNs}$ in buffer with $\mathrm{pH}$ of 6.8 and then in buffer with $\mathrm{pH}$ 4.0. This cycle was repeated for a total of four times, and the amount of HTN3 released at each $\mathrm{pH}$ in function of time was determined by cationic-PAGE, following the protocol previously described.

\subsection{Protein Degradation Study}

Considering that proteins are susceptible to proteolytic degradation inside the oral cavity [40], the protection offered by encapsulation was evaluated in diluted whole saliva. Stimulated whole saliva was collected by chewing a $5 \mathrm{~cm} \times 5 \mathrm{~cm}$ parafilm piece from three healthy individuals, between 9:00 am to 11:00 am, to minimize the effect of circadian rhythm [13], and at least two hours after breakfast. Whole saliva was kept on ice during the collection and then was immediately centrifuged for $10 \mathrm{~min} 14,000 \times \mathrm{g}$ at $4{ }^{\circ} \mathrm{C}$ to separate the bacteria, cells, and other debris from the supernatant containing salivary proteins. The concentration of salivary proteins in the supernatant, referred as whole saliva supernatant (WSS), was quantified using a bicinchoninic acid assay kit. The degradation of free HTN3 was assessed in 10-fold diluted WSS, following the protocol previously reported [6]. Briefly, $50 \mu \mathrm{g}$ of free HTN3 was added to diluted WSS $(100 \mu \mathrm{g}$ salivary protein $/ \mathrm{mL})$ in a final volume of $1 \mathrm{~mL}$. The $\mathrm{pH}$ was adjusted to 6.8 using $1 \mathrm{M} \mathrm{HCl}$ or $1 \mathrm{M} \mathrm{NaOH}$, depending on the $\mathrm{pH}$ of the WSS. Then, an aliquot of $100 \mu \mathrm{L}$ was incubated for $0,0.5,1,2,3$, or $6 \mathrm{~h}$ at $37^{\circ} \mathrm{C}$. At each time point, samples were boiled for $5 \mathrm{~min}$ to terminate proteolytic activity, dried, and desalted. The extent of degradation was quantified after cationic-PAGE, using Image Lab relative quantity tool. Subsequently, the degradation of HTN3-loaded CNs in WSS was assessed by mixing $0.5 \mathrm{~mL}$ of the HTN3-loaded CNs (containing $50 \mu \mathrm{g}$ of HTN3) with diluted WSS $(100 \mu \mathrm{g}$ salivary protein $/ \mathrm{mL})$ to reach a final volume of $1 \mathrm{~mL}$. The final $\mathrm{pH}$ was standardized to 6.8 with $1 \mathrm{M} \mathrm{HCl}$ or $1 \mathrm{M} \mathrm{NaOH}$, depending on the initial $\mathrm{pH}$ of saliva. An aliquot of $100 \mu \mathrm{L}$ was collected after incubation at $37^{\circ} \mathrm{C}$ at the following time points: $0,0.5,1,2,3$, and $6 \mathrm{~h}$. The $\mathrm{pH}$ was adjusted to 3 to release all of the HTN3 within the delivery system. After centrifugation with a $10 \mathrm{kDa}$ Nanosep filter, the filtrate was retrieved and boiled for $5 \mathrm{~min}$ to terminate proteolytic activity. Samples were dried and desalted, followed by cationic-PAGE. The extent of degradation was quantified by Image Lab through the relative quantity tool.

\subsection{Streptococcus mutans Killing Assay and Biofilm Formation}

S. mutans (UA 159) colonies were spiked from blood agar and grown for $14 \mathrm{~h}$ in $10 \mathrm{~mL}$ of tryptone yeast extract broth (TYEB) supplemented with $1 \%$ glucose at $37^{\circ} \mathrm{C}$ and $10 \% \mathrm{CO}_{2}$. After incubation, the bacterial suspension was washed twice with $0.9 \% \mathrm{NaCl}$ and the pellet was resuspended in $1.2 \mathrm{~mL}$ of phosphate-buffered saline (PBS). The optical density (OD) at $600 \mathrm{~nm}$ was adjusted to 1.5, corresponding to a bacterial concentration of $1 \times 10^{9} \mathrm{CFU} / \mathrm{mL}$, based on a growth curve previously done. An aliquot of $0.1 \mathrm{~mL}$ of the bacterial suspension with $1.5 \mathrm{OD}$ reading was added to $9.9 \mathrm{~mL}$ of PBS to obtain a bacterial concentration of $10^{7} \mathrm{CFU} / \mathrm{mL}$. This suspension was then added to an equal volume of a serial dilution series of HTN3 from 0 to $200 \mu \mathrm{M}$ in a 96 -well polypropylene microtiter plate. The samples were then incubated at $37^{\circ} \mathrm{C}$ for $1.5 \mathrm{~h}$. After incubation, each 
sample was diluted $10^{3}$ and $10^{4}$-fold in PBS, and $20 \mu \mathrm{L}$ of each dilution was plated onto Todd Hewitt broth (THB) agar plates. Bacterial viability was assessed by colony counting using comparisons against control samples incubated without HTN3. The IC50 value was calculated based on the dose-response curve and used in the biofilm study described below. To assess the capability of HTN3-loaded CNs to reduce S. mutans biofilm formation on hydroxyapatite (HA) discs, the discs were fixated on the interior of a 24-well polypropylene microtiter plate lid, where the discs were carefully positioned so that the plate lid fits both 24 and 96-well plates. The plate lid was placed to immerse all discs in a 96-well plate filled with $200 \mu \mathrm{L}$ of 5 different treatment solutions ( $n=6$ /group): control (PBS), $7.4 \mu \mathrm{M} \mathrm{HTN3}$, $0.1 \%$ w/v unloaded CNs, $0.1 \% w / v$ CNs containing $7.4 \mu \mathrm{M}$ of encapsulated HTN3, and $12,300 \mathrm{ppm}$ fluoride solution. Treatments were done under constant stirring for $2 \mathrm{~h}$ at $37^{\circ} \mathrm{C}$ to allow the formation of a single-component pellicle onto HA, simulating the formation of the acquired enamel pellicle in the oral cavity. Subsequently, the plate cover was placed on a 24 -well plate with $2 \mathrm{~mL}$ of $0.9 \% w / v ~ \mathrm{NaCl}$ to wash the discs. Afterwards the discs were immersed into $2 \mathrm{~mL}$ of TYEB supplemented with $1 \%$ w/v glucose and $10^{7} \mathrm{CFU} / \mathrm{mL}$ of bacteria. The discs were then incubated at $37^{\circ} \mathrm{C}$ in $10 \% \mathrm{CO}_{2}$ for $8 \mathrm{~h}$. After incubation, the discs were washed again with $\mathrm{NaCl}$, followed by further incubation for $16 \mathrm{~h}$ immersed in $2 \mathrm{~mL}$ of TYEB supplemented with $0.1 \mathrm{mM}$ glucose. Over the next 4 days, the discs were incubated in a repeating cycle between solution 1 and 2 where solution 1 was TYEB supplemented with $1 \% w / v$ sucrose for $8 \mathrm{~h}$, and solution 2 was TYEB supplemented with $0.1 \mathrm{mM}$ glucose for $16 \mathrm{~h}$. On the 6th day, all discs were transferred to separate tubes filled with $1 \mathrm{~mL}$ of PBS, followed by sonication to remove the biofilms off the discs. An aliquot of $0.5 \mathrm{~mL}$ of the suspension was transferred to preweighted tubes and centrifuged at $14,000 \times g$ for $5 \mathrm{~min}$. The supernatant was removed, and the biofilm wet weight was measured. The same suspension was diluted $10^{6}$ and $10^{7}$ times in PBS, and $20 \mu \mathrm{L}$ of each dilution was plated onto THB agar plates, incubated for $48 \mathrm{~h}$ at $37^{\circ} \mathrm{C}$ and $10 \% \mathrm{CO}_{2}$, and then bacterial viability was assessed by colony counting.

\subsection{Statistical Analyses}

Statistical analyses were performed using software Prism 8.0 GraphPad. Biofilm mass and bacterial viability were analyzed by ordinary one-way ANOVA followed by Tukey's multiple comparisons test between each treatment group. The level of significance $(\alpha)$ was set at 0.05 (95\% confidence interval).

\section{Results}

3.1. Results

\subsubsection{Optimization of CNs Formulation}

Four different types of chitosan were investigated to select the best formulation. As shown in Figure 1a, in general the particles were unstable and aggregated at low chitosan to TPP mass ratios. At higher ratios, stable particles were formed and the diameter decreased. Upon further increasing the chitosan to TPP mass ratio, the particle diameter steadily increased for most systems. PDI followed a similar trend as demonstrated in Figure 1b. Zeta potential increased steadily with a corresponding increase in chitosan to TPP ratio. Based on these results, CNs prepared from ultra low MW chitosan were selected as the optimal formulation, because they had the smallest particle diameter (Figure S1), lowest PDI, with a fairly high zeta potential. The particle diameter, PDI, and zeta potential were stable at $4{ }^{\circ} \mathrm{C}$ for at least 60 days (Figure S2). 
(a)

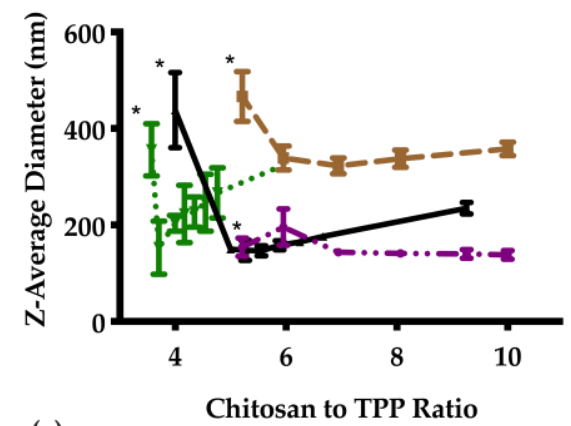

(c)

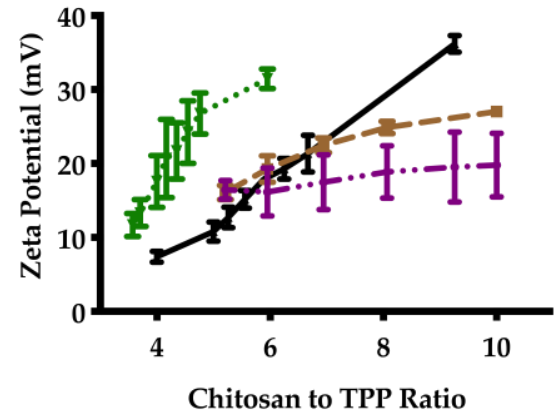

(b)

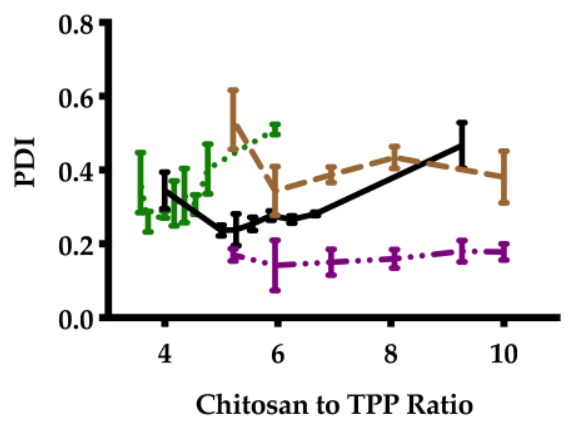

$\rightarrow$ 1. Ultra-Low MW chitosan

- 2. Low MW chitosan (1)

- 3. Low MW chitosan (2)

- 4. Medium MW chitosan

Figure 1. Effect of chitosan to TPP mass ratio on particle properties as measured by DLS: (a) Zaverage diameter; (b) PDI; and (c) Zeta potential. Error bars correspond to the standard deviations on triplicate particle preparations. The particles were unstable and sedimented below a certain ratio (indicated by *), then the diameter generally decreased as the ratio was increased, and finally increased as the ratio was further increased. PDI followed a similar trend, while the zeta potential continually increased due to the increasing cationic charge with increasing chitosan to TPP ratio.

\subsubsection{TEM Images of Unloaded and HTN3-Loaded CNs}

The selected ultra-low CNs were then visualized with TEM. As shown in Figure 2, the CNs had a spherical morphology, and the observed diameters were in good agreement with the data obtained from DLS. There were no obvious differences in size or dispersity among unloaded CNs and those with different loading ratios (Figure S3).

(a)

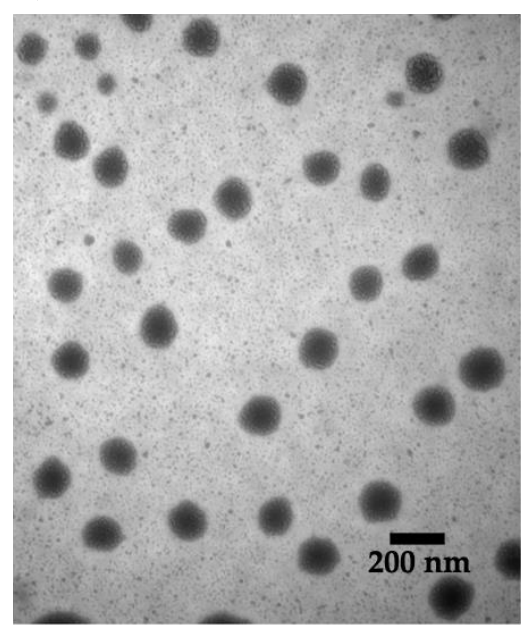

(b)

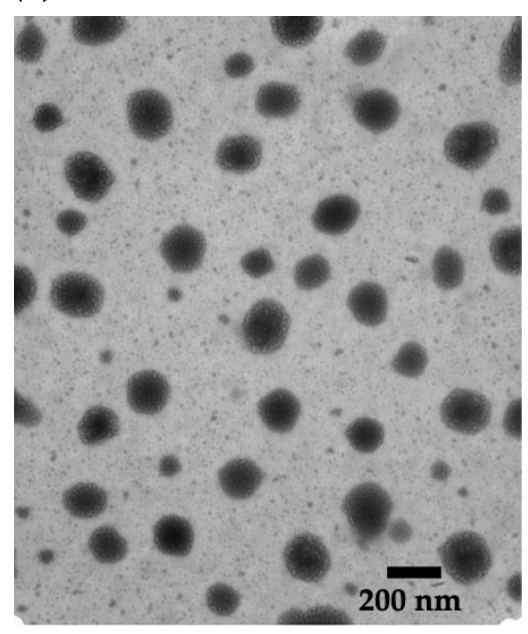

Figure 2. TEM images of CNs: (a) unloaded and (b) HTN3-loaded at a $2 \% w / w$ loading ratio. There are no obvious differences between the samples. 


\subsection{3. pH-Dependent Swelling CNs}

The $\mathrm{pH}$-responsive properties of the unloaded $\mathrm{CNs}$ were examined first by adjusting the $\mathrm{pH}$ from the initial $\mathrm{pH}$ of 6.3 for the formulation to $\mathrm{pH} 3,4$, or 5 . DLS measurements of the $\mathrm{Z}$-average diameters at each $\mathrm{pH}$ indicated greater swelling at lower $\mathrm{pH}$ values (Figure 3a). The CNs swelled from $146 \mathrm{~nm}$ at $\mathrm{pH} 6.3$ to $260 \mathrm{~nm}$ at $\mathrm{pH} 3$. The swelling was rapid at each $\mathrm{pH}$, reaching an equilibrium diameter at $10 \mathrm{~min}$. We also subjected the $\mathrm{CNs}$ suspension to $\mathrm{pH}$-cycling between 6.3 and 4 . Measurements of the Z-average diameter suggested that the CNs were able to selectively swell under acidic conditions and then to contract when the $\mathrm{pH}$ was increased upon removal of the stimulus (Figure 3b). However, there was a general trend towards larger diameters with repeated swelling cycles.

(a)

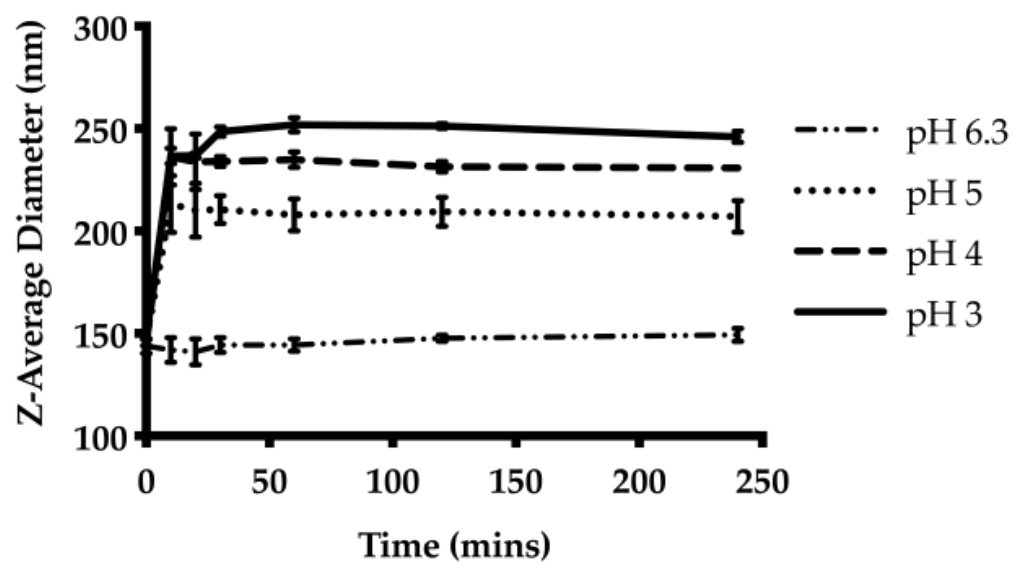

(b)

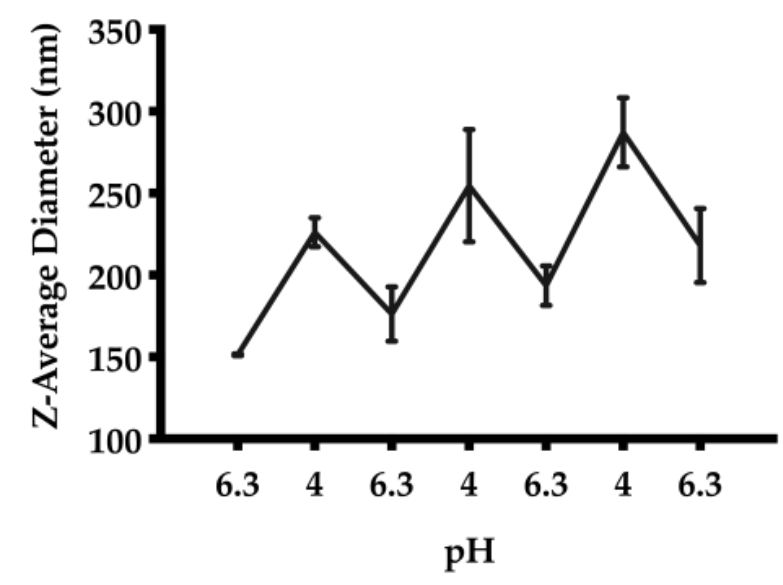

Figure 3. $\mathrm{pH}$-responsive behaviour of the $\mathrm{CNs}$ (a) Z-average diameters over time at different $\mathrm{pH}$ values from 3 to 6.3. The results suggest the degree of swelling is proportional to the acidity of the suspension. The swelling behaviour was also rapid, and reached equilibrium $10 \mathrm{~min}$ after $\mathrm{pH}$ adjustment. (b) The $\mathrm{pH}$-responsive behaviour was further examined through $\mathrm{pH}$ cycling between pH 6.3 and 4. The nanoparticles were able to swell and contract accordingly based on the $\mathrm{pH}$.

\subsection{4. $\mathrm{pH}$-Dependent Release of HTN3 from CNs}

The release kinetics of HTN3 encapsulated CNs were investigated at different $\mathrm{pH}$ values. The highest cumulative amount of HTN3 release was observed at $\mathrm{pH} 3$, and there was minimal release at $\mathrm{pH} 6.8$. On average, at $\mathrm{pH} 3$, the $\mathrm{CNs}$ were able to release $84 \% \pm 7 \%$ of the encapsulated $\mathrm{HTN} 3,58 \% \pm 9 \%$ at $\mathrm{pH} 4,36 \% \pm 3 \%$ at $\mathrm{pH} 5$, and $2 \% \pm 2 \%$ at $\mathrm{pH} 6.8$ over seven separate releases (Figure $4 \mathrm{a}$ ). Thus, the $\mathrm{CNs}$ were able to respond to the environmental $\mathrm{pH}$ changes and release the protein selectively at acidic $\mathrm{pH}$. $\mathrm{pH}$-cycling was also performed to reflect the $\mathrm{pH}$ changes that happen many times in the oral cavity throughout the day. HTN3 loaded CNs were subjected to $\mathrm{pH}$ treatments in the following 
sequence: $6.8,4,6.8,4,6.8,4,6.8$, and 4 . After isolation of released protein and cationicPAGE at each $\mathrm{pH}$ change, protein bands of HTN3 were only observed at $\mathrm{pH} 4$ and were absent at $\mathrm{pH} 6.8$ (Figure $4 \mathrm{~b}$ ). This result shows the $\mathrm{pH}$ selective release for the CNs.

(a)

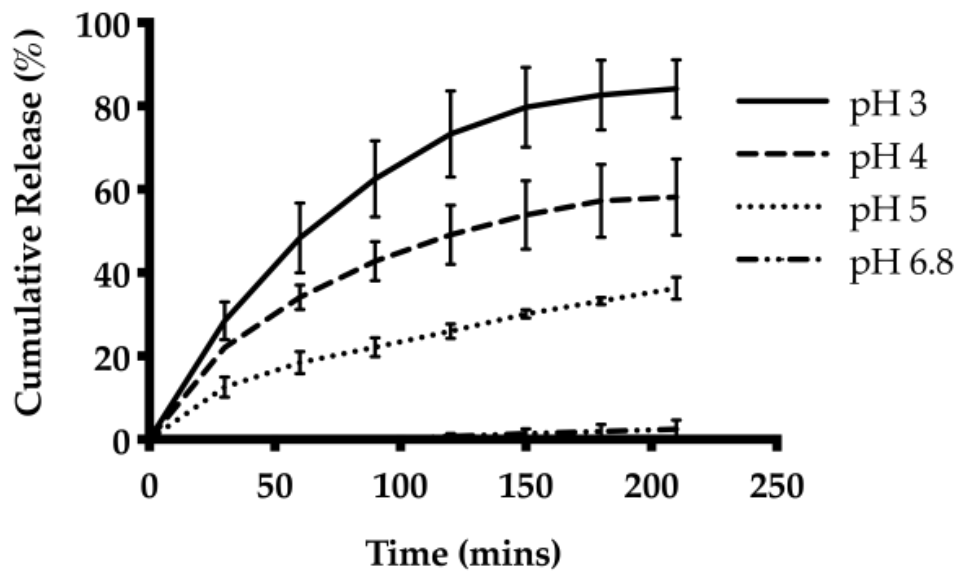

(b)

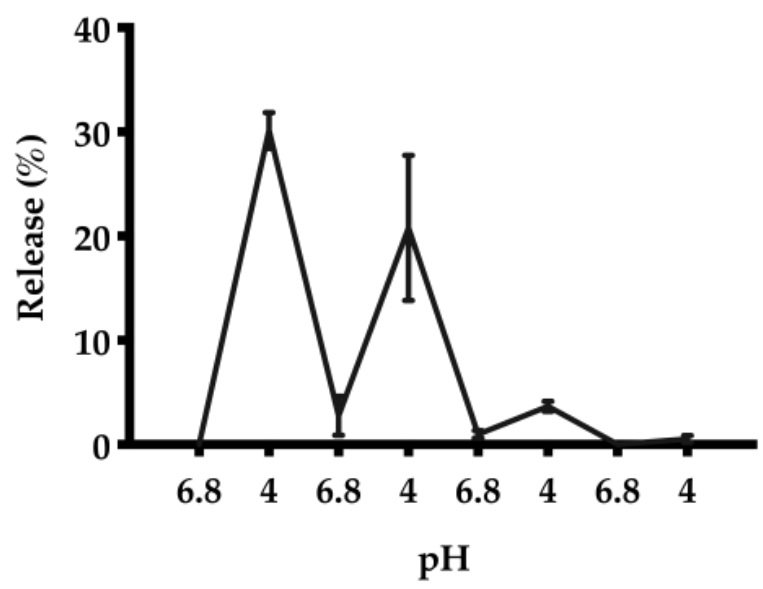

Figure 4. (a) Release of HTN3 from $\mathrm{CNs}$ at different $\mathrm{pH}$ values. The highest extent of release and most rapid release was observed at $\mathrm{pH} 3$, and there was minimal release at $\mathrm{pH}$ 6.8. On average, at $\mathrm{pH} 3$, the $\mathrm{CNs}$ were able to release $84 \% \pm 7 \%$ of the encapsulated protein, $58 \% \pm 9 \%$ at $\mathrm{pH} 4$, $36 \% \pm 3 \%$ at $\mathrm{pH} 5$, and $2 \% \pm 2 \%$ at $\mathrm{pH}$ 6.8. (b) $\mathrm{pH}$ cycling release results show that the $\mathrm{CNs}$ can adapt to environmental $\mathrm{pH}$ changes and can release protein selectively at $\mathrm{pH} 4$ over $3 \mathrm{pH}$ cycles.

\subsubsection{HTN3 Degradation Study in WSS}

To assess the protection offered through encapsulation against enzymatic degradation in the oral cavity, a protein degradation study was conducted in diluted human saliva to compare the degradation kinetics of free HTN3 and HTN3 loaded CNs. The degradation over time was quantified for both free HTN3 and HTN3 loaded CNs (Figure 5 and Table S1). For free HTN3, only $6 \% \pm 5 \%$ of the free HTN3 remained after $2 \mathrm{~h}$, whereas $47 \% \pm 8 \%$ of HTN3 was intact when it was encapsulated in the CNs delivery system. 


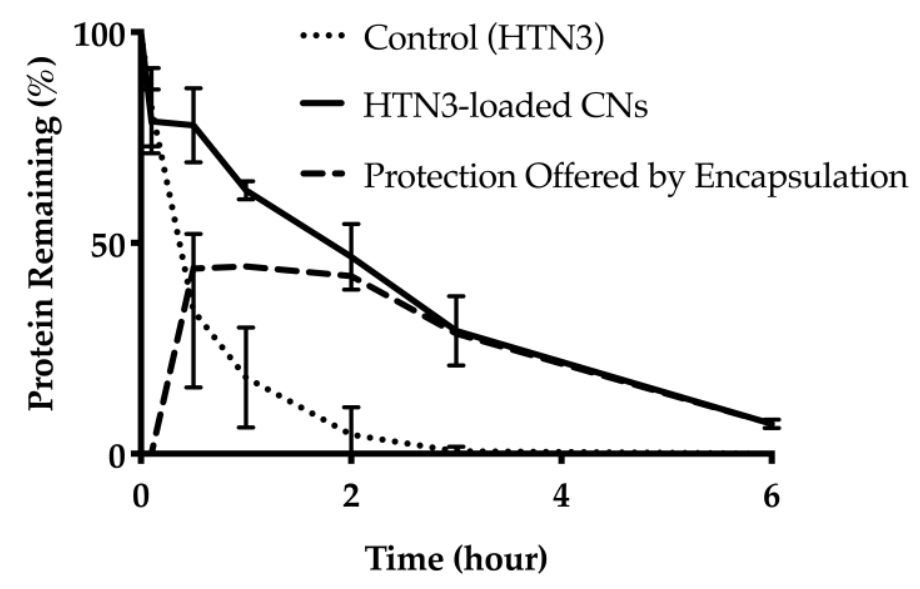

Figure 5. Protein degradation over time for free HTN3 and HTN3-loaded into CNs. For free HTN3, most protein was degraded in $2 \mathrm{~h}$. At the same time point, about half of HTN3 was still intact in the CNs delivery system. The dashed line represents the degree of protection offered through CNs encapsulation.

\subsubsection{Biofilm Formation}

Wet biofilm mass was measured to test the effectiveness of four different treatment groups including $7.4 \mu \mathrm{M}$ HTN3, 0.1\% $w / v$ unloaded CNs, $7.4 \mu \mathrm{M}$ HTN3 in CNs, and the gold standard 12,300 ppm fluoride solution. These groups were compared against PBS as a control group. The control group had an average wet biofilm mass of $15 \pm 2 \mathrm{mg}$, while the mass was $12 \pm 1 \mathrm{mg}$ for HTN3, $8 \pm 2 \mathrm{mg}$ for fluoride, $7 \pm 1 \mathrm{mg}$ for unloaded CNs, and $6 \pm 1$ for HTN3-loaded CNs (Figure 6).

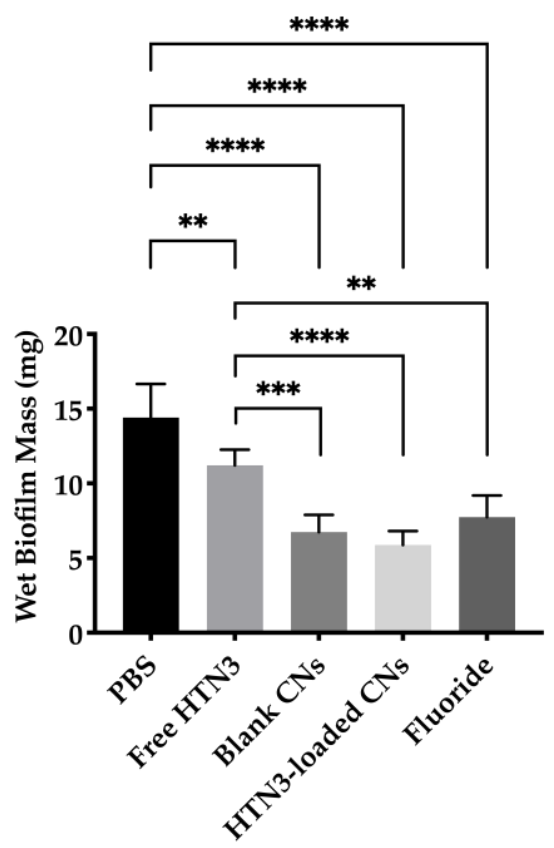

Treatment Groups

Figure 6. Wet biofilm masses for four treatment groups were compared against the control group PBS. All treatment groups led to significantly lower biofilm mass than PBS. Fluoride, blank, and histatin encapsulated CNs performed significantly better than free HTN3 in minimizing biofilm formation, but no significant difference in biofilm mass was observed between these treatment groups $\left.{ }^{* *} p \leq 0.01,{ }^{* * *} p \leq 0.001,{ }^{* * * *} p \leq 0.0001\right)$. 
Bacterial cell viability was also evaluated and presented in Figure 7 . The PBS control led to $5.0 \times 10^{9} \pm 0.4 \times 10^{8} \mathrm{CFU} / \mathrm{mL}$ of viable bacteria, while free HTN3 had $4.6 \times 10^{9} \pm$ $0.3 \times 10^{9} \mathrm{CFU} / \mathrm{mL}$, fluoride had $3.8 \times 10^{9} \pm 0.5 \times 10^{9} \mathrm{CFU} / \mathrm{mL}$, unloaded CNs had $2.7 \times$ $10^{9} \pm 0.4 \times 10^{9} \mathrm{CFU} / \mathrm{mL}$, and HTN3-loaded CNs had $2.3 \times 10^{9} \pm 0.3 \times 10^{9} \mathrm{CFU} / \mathrm{mL}$.

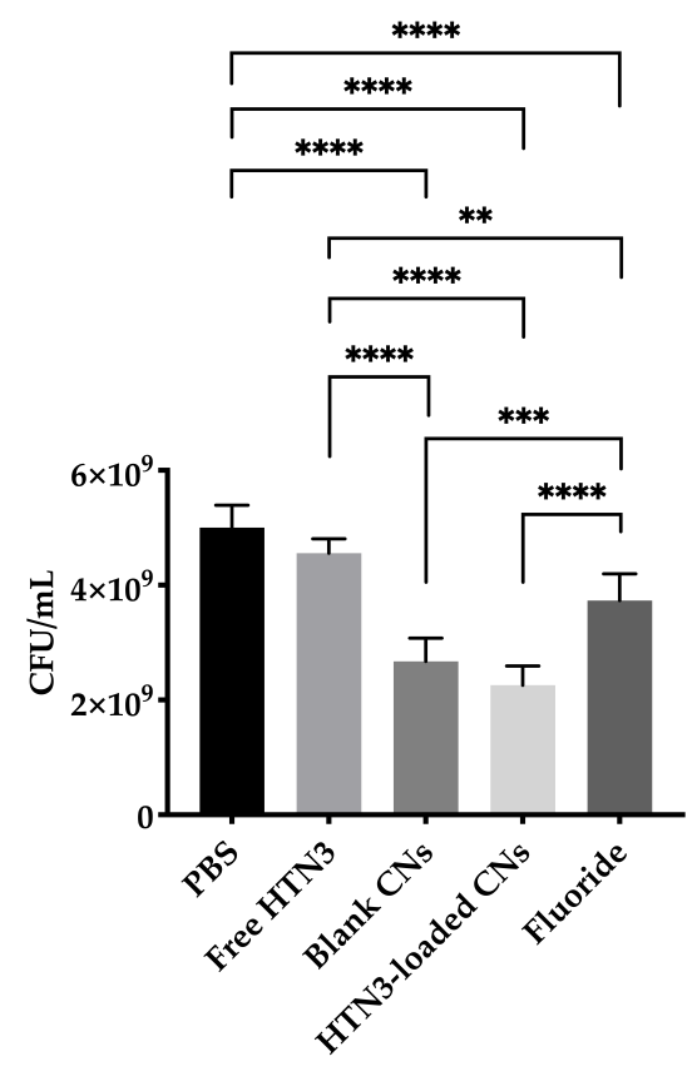

Treatment Groups

Figure 7. Bacterial viability for the four treatment groups were compared against the control group treated with PBS only. While free HTN3 did not control bacterial growth, fluoride treatment significantly decreased bacterial growth. Blank and HTN3-loaded CNs were the most effective at decreasing bacterial population but are insignificantly different from each other $\left(^{* *} p \leq 0.01,{ }^{* * *} p \leq 0.001\right.$, **** $p \leq 0.0001)$.

\section{Discussion}

Salivary proteins such as statherin and HTN have demonstrated several functions that are directly related to the inhibition of dental caries. They inhibit enamel demineralization, promote enamel remineralization, and modulate growth of $S$. mutans [12,41]. However, given the oral cavity can be hostile to proteins due to the high proteolytic activity, these proteins cannot be readily applied as therapeutics for protein-mediated homeostasis. In this study, we produced $\mathrm{pH}$-sensitive $\mathrm{CNs}$, which are able to encapsulate our protein of interest, HTN3, and release it selectively under acidic conditions. The observed pH-sensitivity is important because major oral complications, such as dental caries and dental erosion, occur under acidified conditions. The encapsulation also prolonged the lifetime of HTN3 inside 10-fold diluted human saliva.

The chitosan to TPP mass ratio was first studied systematically to optimize the formulation. At low ratios of chitosan to TPP, the particles were unstable, due to charge neutralization, resulting in visible sedimentation. They became stable as the mass ratio exceeded values ranging from 2:1 to 5:1, depending on the form of chitosan. In general, the smallest diameters and lowest PDI values were observed as a cation:anion molar ratio of about 2:1. As the ratio was further increased, the Z-average diameter increased, which 
can perhaps be attributed to more chitosan per particle or aggregation of the particles. For the same reasons, the PDI also followed a similar trend. For the zeta potential, a steady increase was observed with increasing chitosan to TPP ratios, since chitosan is positively charged. The findings are in agreement with many studies in the literature $[42,43]$.

The optimal formulation was selected based on particle diameter, PDI, and zeta potential. Ideally, it is best to have a formulation with a sub-200 nm diameter nanoparticles, with a relatively low PDI and a high zeta potential. Therefore, the ultra-low MW chitosan formulation at a ratio of 6.94:1 (chitosan to TPP) was chosen as it has the smallest particle diameter of $144 \pm 6 \mathrm{~nm}$, with the lowest PDI of $0.15 \pm 0.04$ and a zeta potential of $18 \pm 4 \mathrm{mV}$. Through a colloidal stability study by time-course of particle size and PDI measurements by DLS, we found that these nanoparticles maintain their average diameter and PDI when the zeta potential is above $15 \mathrm{mV}$. These optimized CNs were visualized by TEM and the average particle diameter estimated from the TEM images was in good agreement with the average particle diameter obtained from DLS. Since HTN3 is a low MW salivary protein, its encapsulation in the CNs did not significantly affect the particle diameter. As shown by the TEM images, there were no significant differences in size or dispersity between the unloaded CNs and those with different HTN3 loading ratios.

The $\mathrm{pH}$-responsive properties of the optimized CNs were also investigated. The extent of swelling under different $\mathrm{pH}$ conditions was studied. The highest degree of swelling was observed at $\mathrm{pH} 3$ and the $\mathrm{CNs}$ remained unchanged at $\mathrm{pH}$ 6.3. The results also demonstrated that the degree of swelling depended on the acidity of the suspension. The swelling response elicited by the $\mathrm{pH}$ stimulus was rapid, suggesting that $\mathrm{CN}$ s were able to quickly respond to $\mathrm{pH}$ changes. The versatility of this $\mathrm{pH}$-responsive property was further examined through $\mathrm{pH}$-cycling between 6.3 and 4, and the results suggested the $\mathrm{CNs}$ delivery system was capable of swelling selectively at acidic $\mathrm{pH}$ and reversed the swelling process upon removal of the $\mathrm{pH}$ stimulus.

The encapsulation loading efficiency of HTN3 was studied at $2 \%, 5 \%$, and 10\% $w / w$ loading ratios of HTN3 to chitosan. The absence of unloaded protein suggested that HTN3 was quantitatively encapsulated in the delivery system at all ratios, which is beneficial, as the loading can therefore be tuned. Cumulative release studies at different $\mathrm{pH}$ values including 3,4,5, and 6.8 were also conducted to assess the extent of release of encapsulated HTN3 from the delivery system. These values were chosen because they reflect the cariogenic conditions promoting different oral diseases. For instance, dental caries initiate at $\mathrm{pH} 5$ and dental erosion occurs at $\mathrm{pH}$ 3. In accordance with the demonstration of the $\mathrm{pH}$-responsive property shown previously, the extent of HTN3 release was proportionate to the acidity of the environment. A maximum cumulative release of $84 \% \pm 7 \%$ was achieved at $\mathrm{pH} 3$ over $210 \mathrm{~min}$, while a minimum release of $2 \% \pm 2 \%$ was observed at $\mathrm{pH} 6.8$ over the same time period. To better mimic the $\mathrm{pH}$ changes in the oral cavity throughout the day, $\mathrm{pH}$-cycling release was performed between $\mathrm{pH} 6.8$ and 4. HTN3-loaded CNs were able to selectively release encapsulated HTN3 at pH 4, and retain the HTN3 at the salivary $\mathrm{pH}$ of 6.8. The ability to selectively release HTN3 under acidic conditions is crucial because throughout the day the salivary $\mathrm{pH}$ fluctuates many times from the consumption of food or beverages $[23,44]$. As saliva becomes acidic following carbohydrate intake, the drop in $\mathrm{pH}$ could trigger the release of HTN3, which promotes oral homeostasis by inhibiting the demineralization process. Salivary $\mathrm{pH}$ would gradually recover to its physiological value due to the buffer capacity of saliva, which would halt HTN3 release from the CNs. Further release of HTN3 would require another sugar challenge, which would drop salivary $\mathrm{pH}$.

Salivary proteins are susceptible to the high proteolytic activity in the oral cavity, which prevent them from being used as potential therapeutics on their own. To evaluate the protection offered through $\mathrm{CN}$ encapsulation against enzymatic degradation, a protein degradation study was performed in 10-fold diluted human saliva. Saliva was diluted to better capture the degradation kinetics of proteins, since at the original concentration the degradation would have happened too rapidly to allow easy measurement of the process. Only $6 \% \pm 5 \%$ of the free HTN3 remained at the 2 -h mark. At the same time 
point, $47 \% \pm 8 \%$ of HTN3 was still present in the CN delivery system. At the 6-h mark, only $7 \% \pm 1 \%$ of HTN3 remained in the delivery system, which could be due to the potential breakdown of the CNs by other salivary proteins. Nevertheless, the delivery system increased the protein survival time significantly. The increase in survival time is important because it allows less frequent administration of the formulation.

Ultimately, a biofilm model was applied to evaluate the therapeutic effect of HTN3loaded $C N s$ against $S$. mutans biofilm formation on hydroxyapatite discs. S. mutans was chosen because it is a major contributor responsible for the initiation and development of tooth decay $[23,45]$. It metabolizes sucrose to produce sticky polysaccharides that allow the bacteria to aggregate and adhere to the tooth enamel, forming a biofilm. The biofilm, together with frequent sugar intake promotes fermentation of dietary sugar into acidic products. Persistence of the resulting acidic conditions favours the proliferation of acidogenic bacteria. The low $\mathrm{pH}$ environment in the biofilm initiates the dental caries process $[23,46]$. Hydroxyapatite is a mineral composed of calcium phosphate, which greatly resembles human hard tissues including bone and tooth enamel in composition and morphology [47]. It is also the most stable calcium phosphate mineral under physiological conditions [48]. Therefore it has been extensively used in oral applications, such as pellicle formation and biofilm formation [49,50].

Two key factors used to evaluate biofilm growth are biofilm mass and bacterial cell viability. Effective treatment should result in low biofilm mass and reduced bacterial cell viability. For biofilm mass measurements, based on the ANOVA analysis and Tukey's multiple comparisons test, all four treatment groups resulted in significantly reduced biofilm mass compared to the control group. Fluoride together with unloaded and HTN3loaded CNs were significantly more effective than free HTN3. However, no significant difference was observed between the HTN3-loaded CNs and unloaded CNs. Both of these treatments successfully lowered the biofilm mass by at least half. Bacterial cell viability was also determined for all treatment groups. Free HTN3 was not effective at reducing bacterial cell viability and did not perform better than the control group. Fluoride, unloaded, and HTN3-loaded CNs significantly reduced cell viability when compared against the control group. Fluoride was significantly more effective when compared against HTN3. Unloaded and HTN3-loaded CNs were the most competent treatment groups. They reduced cell viability in half, but their performance in reducing bacterial population were not significantly different from one another. While these results suggest that $\mathrm{CNs}$ alone can potentially control bacterial population growth, further studies that encapsulate greater HTN3 concentrations within $\mathrm{CNs}$, or reduce the amount of $\mathrm{CNs}$ while maintaining HTN3 concentrations are required. In addition, CNs are known to exhibit antimicrobial effects against $S$. mutans [51]. Another possible explanation would be $\mathrm{CNs}$ alone already prevented the initiation of demineralization, therefore there was no steep drop in $\mathrm{pH}$ to trigger HTN3 release from the CNs.

\section{Conclusions}

In conclusion, the results of this study demonstrated the $\mathrm{pH}$-responsive properties of the CNs. The $\mathrm{CNs}$ were also able to offer protection against enzymatic degradation in comparison to free HTN3. While HTN3-loaded CNs had successfully reduced biofilm growth as reflected by reduced biofilm mass and bacterial cell viability, these particles did not significantly outperform unloaded CNs. Future studies should include use of the biofilm model to characterize the contribution of HTN3 within CNs and CNs alone in controlling bacterial population. Nonetheless, this work has shown that CNs can be used as a protein carrier for oral applications, especially for complications involving acidic environments. This delivery system can also be applied to encapsulate other salivary proteins for oral delivery. The ultimate goal of studying protein encapsulation within $\mathrm{CNs}$ is to integrate multifunctional salivary proteins into daily dental hygiene products like toothpaste and mouthwash to provide a preventative approach to address dental caries. Altogether, our results show that a $\mathrm{pH}$-sensitive delivery system that can release salivary 
proteins under oral conditions can be achieved by utilizing a biodegradable, biocompatible, and naturally derived polymer like chitosan.

Supplementary Materials: The following are available online at https://www.mdpi.com/article/ 10.3390/nano11041028/s1, Figure S1: Volume distribution of the ultra-low MW CNs at chitosan to TPP mass ratio of 6.94. There is a small batch to batch variability; Figure S2: CNs were stored at $4{ }^{\circ} \mathrm{C}$, and three parameters including (a) Z-average diameter, (b) PDI, and (c) Zeta potential were measured by DLS routinely over the course of 60 days. The consistency of obtained data suggest the nanoparticles are stable; Figure S3: TEM images of (a) blank chitosan nanoparticles, (b) HTN3 loaded chitosan nanoparticles with a $\%$ w/w loading ratio, (c) HTN3 loaded chitosan nanoparticles with a $5 \% w / w$ loading ratio, and (d) HTN3 loaded chitosan nanoparticles with a 10\% w/w loading ratio. No significant variance in size or dispersity was observed among blank chitosan nanoparticles and those with different loading ratios; Table S1: Protein degradation over time for free HTN3 and HTN3-loaded into CNs.

Author Contributions: Conceptualization, E.R.G. and W.L.S.; methodology, Y.Z., L.M.M., Y.X., E.R.G. and W.L.S.; validation, Y.Z.; formal analysis, Y.Z.; investigation, Y.Z.; resources, L.M.M. and Y.X.; data curation, Y.Z.; writing—original draft preparation, Y.Z.; writing—review and editing, Y.Z., L.M.M., E.R.G. and W.L.S.; visualization, Y.Z.; supervision, E.R.G. and W.L.S.; project administration, Y.Z., L.M.M. and Y.X.; funding acquisition, E.R.G. and W.L.S. All authors have read and agreed to the published version of the manuscript.

Funding: This research was funded by Canadian Institutes of Health Research-CIHR, grant numbers 106657 and 400347; Canada Foundation for Innovation-Leaders Opportunity Fund, grant number 25116.

Institutional Review Board Statement: The study was conducted according to the guidelines of the Declaration of Helsinki, and approved by the Human Research Ethics Committee at The University of Western Ontario (protocol number 16181E, 6 June 2016).

Informed Consent Statement: Informed consent was obtained from all subjects involved in the study.

Data Availability Statement: The data presented in this study are available on request from the corresponding author.

Acknowledgments: The authors acknowledge the staffs from Biotron's Imaging and Microscopy Facility at The University of Western Ontario for technical assistance with TEM imaging. This paper is based on a thesis submitted by the first author to the School of Biomedical Engineering, The University of Western Ontario, London ON, Canada, in partial fulfillment of the requirements for the Master's program in biomedical engineering [52].

Conflicts of Interest: The authors declare no conflict of interest.

\section{References}

1. Siqueira, W.L.; Dawes, C. The salivary proteome: Challenges and perspectives. Proteom. Clin. Appl. 2011, 5, 575-579. [CrossRef]

2. Scarano, E.; Fiorita, A.; Picciotti, P.M.; Passali, G.C.; Calò, L.; Cabras, T.; Inzitari, R.; Fanali, C.; Messana, I.; Castagnola, M.; et al. Proteomics of saliva: Personal experience. Acta Otorhinolaryngol. 2010, 30, 125-130.

3. Mandel, I.D. The Functions of Saliva. J. Dent. Res. 1987, 66, 623-627. [CrossRef] [PubMed]

4. Siqueira, W.L.; Zhang, W.; Helmerhorst, E.J.; Gygi, S.P.; Oppenheim, F.G. Identification of Protein Components ininvivoHuman Acquired Enamel Pellicle Using LC-ESI-MS/MS. J. Proteome Res. 2007, 6, 2152-2160. [CrossRef] [PubMed]

5. Oppenheim, F.G.; Salih, E.; Siqueira, W.L.; Zhang, W.; Helmerhorst, E.J. Salivary Proteome and Its Genetic Polymorphisms. Ann. N. Y. Acad. Sci. 2007, 1098, 22-50. [CrossRef] [PubMed]

6. Xiuli, S.; Erdjan, S.; Oppenheim, F.G.; Helmerhorst, E.J. Kinetics of histatin proteolysis in whole saliva and the effect on bioactive domains with metal-binding, antifungal, and wound-healing properties. FASEB J. 2009, 23, 2691-2701. [CrossRef] [PubMed]

7. Siqueira, W.L.; Lee, Y.H.; Xiao, Y.; Held, K.; Wong, W. Identification and characterization of histatin 1 salivary complexes by using mass spectrometry. Proteomics 2012, 12, 3426-3435. [CrossRef] [PubMed]

8. Gusman, H.; Leone, C.; Helmerhorst, E.J.; Nunn, M.; Flora, B.; Troxler, R.F.; Oppenheim, F.G. Human salivary gland-specific daily variations in histatin concentrations determined by a novel quantitation technique. Arch. Oral Biol. 2004, 49, 11-22. [CrossRef]

9. Shimotoyodome, A.; Kobayashi, H.; Tokimitsu, I.; Matsukubo, T.; Takaesu, Y. Statherin and Histatin 1 Reduce Parotid Sali-vaPromoted Streptococcus Mutans Strain MT8148 Adhesion to Hydroxyapatite Surfaces. Caries Res. 2006, 40, 403-411. [CrossRef] 
10. Puri, S.; Edgerton, M. How Does It Kill? Understanding the Candidacidal Mechanism of Salivary Histatin Eukaryot. Cell 2014, 13, 958-964. [CrossRef]

11. Basiri, T.; Johnson, N.; Moffa, E.; Mulyar, Y.; Nunes, P.S.; Machado, M.; Siqueira, W. Duplicated or Hybridized Peptide Functional Domains Promote Oral Homeostasis. J. Dent. Res. 2017, 96, 1162-1167. [CrossRef] [PubMed]

12. Helmerhorst, E.; Alagl, A.; Siqueira, W.; Oppenheim, F. Oral fluid proteolytic effects on histatin 5 structure and function. Arch. Oral Biol. 2006, 51, 1061-1070. [CrossRef]

13. McDonald, E.E.; Goldberg, H.A.; Tabbara, N.; Mendes, F.M.; Siqueira, W.L. Histatin 1 Resists Proteolytic Degradation when Adsorbed to Hydroxyapatite. J. Dent. Res. 2010, 90, 268-272. [CrossRef]

14. Mihu, M.R.; Sandkovsky, U.; Han, G.; Friedman, J.M.; Nosanchuk, J.D.; Martinez, L.R. The use of nitric oxide releasing nanoparticles as a treatment againstAcinetobacter baumanniiin wound infections. Virulence 2010, 1, 62-67. [CrossRef]

15. Yang, X.; Grailer, J.J.; Pilla, S.; Steeber, U.A.; Gong, S. Tumor-Targeting, pH-Responsive, and Stable Unimolecular Micelles as Drug Nanocarriers for Targeted Cancer Therapy. Bioconj. Chem. 2010, 21, 496-504. [CrossRef]

16. Shen, M.; Huang, Y.; Han, L.; Qin, J.; Fang, X.; Wang, J.; Yang, V.C. Multifunctional drug delivery system for targeting tumor and its acidic microenvironment. J. Control. Release 2012, 161, 884-892. [CrossRef] [PubMed]

17. Xiong, M.-H.; Li, Y.-J.; Bao, Y.; Yang, X.-Z.; Hu, B.; Wang, J. Bacteria-Responsive Multifunctional Nanogel for Targeted Antibiotic Delivery. Adv. Mater. 2012, 24, 6175-6180. [CrossRef]

18. Lee, E.S.; Shin, H.J.; Na, K.; Bae, Y.H. Poly(l-histidine)-PEG block copolymer micelles and pH-induced destabilization. J. Control. Release 2003, 90, 363-374. [CrossRef]

19. Basel, M.T.; Shrestha, T.B.; Troyer, D.L.; Bossmann, S.H. Protease-Sensitive, Polymer-Caged Liposomes: A Method for Making Highly Targeted Liposomes Using Triggered Release. ACS Nano 2011, 5, 2162-2175. [CrossRef]

20. Chen, K.-J.; Chaung, E.-Y.; Wey, S.-P.; Lin, K.-J.; Cheng, F.; Lin, C.-C.; Liu, H.-L.; Tseng, H.-W.; Liu, C.-P.; Wei, M.-C.; et al. Hyperthermia-Mediated Local Drug Delivery by a Bubble-Generating Liposomal System for Tumor-Specific Chemotherapy. ACS Nano 2014, 8, 5105-5115. [CrossRef] [PubMed]

21. Fan, B.; Gillies, E.R. Poly(ethyl glyoxylate)-Poly(ethylene oxide) Nanoparticles: Stimuli-Responsive Drug Release via End-to-End Polyglyoxylate Depolymerization. Mol. Pharm. 2017, 14, 2548-2559. [CrossRef]

22. Nikaido, T.; Moriya, K.; Hiraishi, N.; Ikeda, M.; Kitasako, Y.; Foxton, R.M.; Tagami, J. Surface Analysis of Dentinal Caries in Primary Teeth Using a PH-Imaging Microscope. Dent. Mater. J. 2004, 23, 628-632. [CrossRef] [PubMed]

23. Bowen, W.H.; Tenuta, L.M.A.; Koo, H.; Cury, J.A. Dental Caries: Etiology and Pathogenesis. In Oral Microbiology and Immunology, 3rd ed.; Lamont, R.J., Hajishengalis, G.M., Koo, H., Jenkinson, H.F., Eds.; ASM Press: Washington, DC, USA, 2019 ; pp. $251-265$.

24. Dash, M.; Chiellini, F.; Ottenbrite, R. Chitosan-A versatile semi-synthetic polymer in biomedical applications. Prog. Polym. Sci. 2011, 36, 981-1014. [CrossRef]

25. Raafat, D.; Sahl, H.-G. Chitosan and its antimicrobial potential—a critical literature survey. Microb. Biotechnol. 2009 , 2, 186-201. [CrossRef] [PubMed]

26. Tang, W.J.; Fernandez, J.G.; Sohn, J.J.; Amemiya, C.T. Chitin Is Endogenously Produced in Vertebrates. Curr. Biol. 2015, 25, 897-900. [CrossRef]

27. Souza, M.P.; Vaz, A.F.; Correia, M.T.S.; Cerqueira, M.A.; Vicente, A.A.; Carneiro-Da-Cunha, M.G. Quercetin-Loaded Lecithin/Chitosan Nanoparticles for Functional Food Applications. Food Bioprocess Technol. 2014, 7, 1149-1159. [CrossRef]

28. Bugnicourt, L.; Ladavière, C. Interests of chitosan nanoparticles ionically cross-linked with tripolyphosphate for biomedical applications. Prog. Polym. Sci. 2016, 60, 1-17. [CrossRef]

29. Olivera, S.; Muralidhara, H.B.; Venkatesh, K.; Guna, V.K.; Gopalakrishna, K. Potential applications of cellulose and chitosan nanoparticles/composites in wastewater treatment: A review. Carbohydr. Polym. 2016, 153, 600-618. [CrossRef] [PubMed]

30. Carvalho, T.S.; Lussi, A. Combined effect of a fluoride-, stannous-and chitosan-containing toothpaste and stannous-containing rinse on the prevention of initial enamel erosion-abrasion. J. Dent. 2014, 42, 450-459. [CrossRef]

31. Costa, E.; Silva, S.; Madureira, A.; Cardelle-Cobas, A.; Tavaria, F.; Pintado, M. A comprehensive study into the impact of a chitosan mouthwash upon oral microorganism's biofilm formation in vitro. Carbohydr. Polym. 2014, 101, 1081-1086. [CrossRef]

32. Kean, T.; Thanou, M. Biodegradation, biodistribution and toxicity of chitosan. Adv. Drug Deliv. Rev. 2010, 62, 3-11. [CrossRef]

33. Thandapani, G.; Prasad, S.; Sudha, P.N.; Sukumaran, A. Size optimization and in vitro biocompatibility studies of chitosan nanoparticles. Int. J. Biol. Macromol. 2017, 104, 1794-1806. [CrossRef]

34. Cha, J.; Lee, W.B.; Park, C.R.; Cho, Y.W.; Ahn, C.-H.; Kwon, I.C. Preparation and characterization of cisplatin-incorporated chitosan hydrogels, microparticles, and nanoparticles. Macromol. Res. 2006, 14, 573-578. [CrossRef]

35. Wang, X.; Zheng, C.; Wu, Z.; Teng, D.; Zhang, X.; Wang, Z.; Li, C. Chitosan-NAC nanoparticles as a vehicle for nasal absorption enhancement of insulin. J. Biomed. Mater. Res. Part B Appl. Biomater. 2009, 88, 150-161. [CrossRef]

36. Ridolfi, D.M.; Marcato, P.D.; Justo, G.Z.; Cordi, L.; Machado, D.; Durán, N. Chitosan-solid lipid nanoparticles as carriers for topical delivery of tretinoin. Colloids Surf. B Biointerfaces 2012, 93, 36-40. [CrossRef]

37. Janes, K.A.; Fresneau, M.P.; Marazuela, A.; Fabra, A.; Alonso, M.J. Chitosan nanoparticles as delivery systems for doxorubicin. J. Control. Release 2001, 73, 255-267. [CrossRef]

38. Calvo, P.; Vila-Jato, J.L.; Alonso, M.J. Novel hydrophilic chitosan-polyethylene oxide nanoparticles as protein carriers. J. Appl. Polym. Sci. 1997, 63, 125-132. [CrossRef] 
39. Siqueira, W.L.; Margolis, H.C.; Helmerhorst, E.J.; Mendes, F.M.; Oppenheim, F.G. Evidence of Intact Histatins in thein vivoAcquired Enamel Pellicle. J. Dent. Res. 2010, 89, 626-630. [CrossRef]

40. Nakamura, M.; Slots, J. Salivary enzymes. J. Periodontal Res. 1983, 18, 559-569. [CrossRef] [PubMed]

41. Siqueira, W.; Custodio, W.; McDonald, E. New Insights into the Composition and Functions of the Acquired Enamel Pellicle. J. Dent. Res. 2012, 91, 1110-1118. [CrossRef]

42. Fan, W.; Yan, W.; Xu, Z.; Ni, H. Formation mechanism of monodisperse, low molecular weight chitosan nanoparticles by ionic gelation technique. Colloids Surf. B Biointerfaces 2012, 90, 21-27. [CrossRef]

43. Jonassen, H.; Kjøniksen, A.-L.; Hiorth, M. Stability of Chitosan Nanoparticles Cross-Linked with Tripolyphosphate. Biomacromolecules 2012, 13, 3747-3756. [CrossRef]

44. Bowen, W.H. The Stephan Curve revisited. Odontology 2012, 101, 2-8. [CrossRef]

45. Garcia, S.; Blackledge, M.; Michalek, S.; Su, L.; Ptacek, T.; Eipers, P.; Morrow, C.; Lefkowitz, E.; Melander, C.; Wu, H. Targeting of Streptococcus mutans Biofilms by a Novel Small Molecule Prevents Dental Caries and Preserves the Oral Microbiome. J. Dent. Res. 2017, 96, 807-814. [CrossRef] [PubMed]

46. Argimón, S.; Caufield, P.W. Distribution of Putative Virulence Genes in Streptococcus mutans Strains Does Not Correlate with Caries Experience. J. Clin. Microbiol. 2011, 49, 984-992. [CrossRef]

47. Wei, G.; Ma, P.X. Structure and properties of nano-hydroxyapatite/polymer composite scaffolds for bone tissue engineering. Biomaterials 2004, 25, 4749-4757. [CrossRef] [PubMed]

48. Kalita, S.J.; Bhardwaj, A.; Bhatt, H.A. Nanocrystalline calcium phosphate ceramics in biomedical engineering. Mater. Sci. Eng. C 2007, 27, 441-449. [CrossRef]

49. Smith, A.M.V.; Bowen, W.H. In situ studies of pellicle formation on hydroxyapatite discs. Arch. Oral Biol. 2000, 45, $277-291$. [CrossRef]

50. Takeshita, T.; Yasui, M.; Shibata, Y.; Furuta, M.; Saeki, Y.; Eshima, N.; Yamashita, Y. Dental plaque development on a hydroxyapatite disk in young adults observed by using a barcoded pyrosequencing approach. Sci. Rep. 2015, 5, 8136. [CrossRef] [PubMed]

51. De Paz, L.E.C.; Resin, A.; Howard, K.A.; Sutherland, D.S.; Wejse, P.L. Antimicrobial Effect of Chitosan Nanoparticles on Streptococcus mutans Biofilms. Appl. Environ. Microbiol. 2011, 77, 3892-3895. [CrossRef] [PubMed]

52. Zhu, Y. A pH-Sensitive Delivery System for the Prevention of Dental Caries Using Salivary Proteins. Master's thesis, The University of Western Ontario, London, ON, Canada, 2019. Available online: https://ir.lib.uwo.ca/etd/6227 (accessed on 15 April 2021). 